University of Nebraska - Lincoln

DigitalCommons@University of Nebraska - Lincoln

USDA Wildlife Services - Staff Publications

U.S. Department of Agriculture: Animal and Plant Health Inspection Service

$5-18-2021$

\title{
Landscape Genetics of American Beaver in Coastal Oregon
}

\author{
Clinton W. Epps \\ Oregon State University \\ Vanessa M. Petro \\ Oregon State University \\ Tyler G. Creech \\ Oregon State University \\ Rachel S. Crowhurst \\ Oregon State University \\ Matthew J. Weldy \\ Oregon State University
}

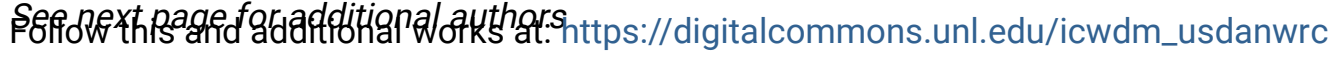

Part of the Natural Resources and Conservation Commons, Natural Resources Management and Policy Commons, Other Environmental Sciences Commons, Other Veterinary Medicine Commons, Population Biology Commons, Terrestrial and Aquatic Ecology Commons, Veterinary Infectious Diseases Commons, Veterinary Microbiology and Immunobiology Commons, Veterinary Preventive Medicine, Epidemiology, and Public Health Commons, and the Zoology Commons

Epps, Clinton W.; Petro, Vanessa M.; Creech, Tyler G.; Crowhurst, Rachel S.; Weldy, Matthew J.; and Taylor, Jimmy D., "Landscape Genetics of American Beaver in Coastal Oregon" (2021). USDA Wildlife Services Staff Publications. 2528.

https://digitalcommons.unl.edu/icwdm_usdanwrc/2528

This Article is brought to you for free and open access by the U.S. Department of Agriculture: Animal and Plant Health Inspection Service at DigitalCommons@University of Nebraska - Lincoln. It has been accepted for inclusion in USDA Wildlife Services - Staff Publications by an authorized administrator of DigitalCommons@University of Nebraska - Lincoln. 


\section{Authors}

Clinton W. Epps, Vanessa M. Petro, Tyler G. Creech, Rachel S. Crowhurst, Matthew J. Weldy, and Jimmy D. Taylor 


\title{
Landscape Genetics of American Beaver in Coastal Oregon
}

\author{
CLINTON W. EPPS D, ${ }^{1}$ Department of Fisheries and Wildlife, Oregon State University, Corvallis, OR 97331, USA \\ VANESSA M. PETRO D, Department of Forest Ecosystems and Society, Oregon State University, 321 Richardson Hall, Corvallis, OR 97331, USA \\ TYLER G. CREECH, ${ }^{2}$ Department of Fisheries and Wildlife, Oregon State University, Corvallis, OR 97331, USA \\ RACHEL S. CROWHURST, Department of Fisheries and Wildife, Oregon State University, Corvallis, OR 97331, USA \\ MATTHEW J. WELDY (D, ${ }^{3}$ Department of Fisheries and Wildlife, Oregon State University, Corvallis, OR 97331, USA \\ JIMMY D. TAYLOR (D), USDA, APHIS, National Wildlife Research Center, Oregon Field Station, 321 Richardson Hall, Corvallis, OR 97331, USA
}

\begin{abstract}
American beaver (Castor canadensis) have been translocated for population restoration, reduction of human-wildlife conflict, and enhancement of ecosystem function. Yet few studies have assessed dispersal of beaver, making it difficult to determine at what scale translocations are appropriate. Genetic studies can provide inferences about gene flow, and thus dispersal. We used a landscape genetic approach to evaluate whether landscape features influenced gene flow among beaver in the Coast Range of western Oregon, USA, using samples collected April-September 2014. We collected genetic samples from live-captured $(n=232)$, road-killed $(n=2)$ and trapper-provided $(n=58)$ tissue samples and genotyped them at 10 microsatellite loci. We mapped records of beaver translocations into or within the study area during the twentieth century to consider the effect of those movements on genetic structure. We used population assignment tests to delimit genetic clusters, evaluated correspondence of those clusters with watershed boundaries and translocation history, and then estimated differentiation between clusters and between watersheds using model-based and model-free approaches. We evaluated how individual genetic differences varied with geographic distance, and investigated related pairs within clusters. We developed landscape resistance models incorporating slope, distance to water, and watershed boundaries at 2 scales, and estimated effective distances between sample locations with least cost path and circuit theoretic analyses. We evaluated the correlation of individual genetic distances with effective distances using a pseudo-bootstrapping approach. Landscape genetic models did not explain spatial variation in genetic structure better than geographic distance, but hierarchical genetic structure corresponded with watershed boundaries and suggested influences from historical translocations. Pairwise individual genetic distances were positively correlated with geographic distances to $61 \mathrm{~km}$; highly-related pairs mostly were detected $<1 \mathrm{~km}$ apart (median $=1.0 \mathrm{~km}, \bar{x}=14.6 \pm 2.3[\mathrm{SE}] \mathrm{km}, n=77$ ). We concluded that slope and distance to water did not strongly limit dispersal and gene flow by beaver in this system, but concordance of genetic structure with watershed boundaries suggests that dispersal is more common within than between watersheds. Genetic differentiation of beaver within this topographically complex system was much greater than reported in a study at similar spatial scales in relatively flat topography. We recommend that translocation efforts of American beaver in topographically complex landscapes occur within watersheds when possible but conclude that dispersal can occur across watersheds. (c) 2021 The Wildlife Society. This article is a U.S. Government work and is in the public domain in the USA.
\end{abstract}

KEY WORDS Castor canadensis, Coast Range, coho salmon, genetic structure, isolation by distance, landscape resistance, American beaver, Oncorbynchus kisutch.

The American beaver (Castor canadensis; beaver) was overharvested and locally extirpated during the sixteenth through nineteenth centuries (Kebbe 1960). This legacy sometimes overshadows the successful restoration of beaver

Received: 14 April 2020; Accepted: 18 May 2021

${ }^{1}$ E-mail: clinton.epps@oregonstate.edu

${ }^{2}$ Present address: Center for Large Landscape Conservation, Bozeman, MT 59715, USA

${ }^{3}$ Present address: Pacific Northwest Research Station, USDA Forest Service, Corvallis, OR 97331, USA populations throughout North America in the twentieth century and the potential for beaver to colonize empty habitat through dispersal (Lizarralde et al. 2008). Although there is no known estimate of beaver population size in North America, beaver currently are managed as furbearers with established seasons and bag limits for trapping or hunting in every state of the continental United States and all Canadian provinces, and this species is considered stable and of least concern by the International Union for Conservation of Nature (Cassola 2016). Beaver are also managed to provide ecosystem services (Law et al. 2016, 
McCaffery and Eby 2016) and to address human-wildlife conflict (Taylor et al. 2017), both stem from dam-building behavior (Pollock et al. 2014, Petro et al. 2015).

Stream restoration involving beaver has received growing interest in the western United States (Law et al. 2016), although the desire to implement field projects has outpaced supporting research (Pilliod et al. 2018), and its effectiveness is not well documented (Nash et al. 2021). Desired outcomes of restoration involving beaver may include restoring floodplain connectivity, improving grazing opportunities for livestock, storing above-ground water, mitigating increasing aridity (Hood and Bayley 2008), or providing habitat for sensitive species (Pollock et al. 2014) such as coho salmon (Oncorhynchus kisutch). Beaver translocation is the most-reported method for such restoration; translocation also is frequently used to remove beaver causing property damage or perceived as overabundant, although such translocations are not always legal (Pilliod et al. 2018).

Efforts to reestablish beaver for stream restoration or harvest, relocate individuals involved in human-wildlife conflict, or control the spread of beaver where they are nonnative (Lizarralde et al. 2008, Parker et al. 2012) should consider the dispersal potential of beaver. Otherwise, nuisance beaver may return, translocations may occur needlessly in places where natural dispersal would serve, or control efforts might be inappropriately distributed. Dispersal and movement of beaver have been described in several systems using radio-telemetry. McNew and Woolf (2005) reported mean dispersal distances of $5.9 \mathrm{~km}$ along waterways and $1.7 \mathrm{~km}$ over land in southern Illinois, USA; most dispersal movements were $<5 \mathrm{~km}$, but movements of $20.9 \mathrm{~km}$ and $14.2 \mathrm{~km}$ were documented. DeStefano et al. (2006) reported mean dispersal distances in Massachusetts to be $4.5 \mathrm{~km}$ along waterways $(11.4 \mathrm{~km}$ max.) and $3.5 \mathrm{~km}$ over land $(8.0 \mathrm{~km}$ max.). Intrinsic factors also influence dispersal; movement rates vary with age (McClintic et al. 2014), foray behavior in European beaver (Castor fiber) varies with territory-holding status (Mayer et al. 2017), and population density influences dispersal behavior in beaver (DeStefano et al. 2006). Yet such studies rarely capture long-distance movements and are likely to be specific to particular landscapes.

Landscape genetic studies (Manel and Holderegger 2013) may provide an alternative means of gaining insight on dispersal. By sampling DNA from individuals as widely and evenly as possible across a region, and characterizing genotypes using highly variable markers such as microsatellites or single-nucleotide polymorphisms (SNPs), genetic differences among individuals or groups can be modeled as a function of hypothesized barriers or landscape features that may resist or facilitate dispersal, and thus gene flow (Cushman et al. 2006, Epps et al. 2007). Landscape features, which include variation in vegetation, landform, terrain, and human-made structures such as roads, are expected to influence dispersal of terrestrial species (Spear et al. 2010), particularly those that are habitat specialists, not well-adapted for efficient long-distance movements, or sensitive to predation risk that varies across cover types (Epps and Keyghobadi 2015). Beaver are commonly preyed on by mountain lions (Puma concolor) and other large predators (Elbroch et al. 2017), and experience significant human-induced mortality (DeStefano et al. 2006). Those factors, and the variations in landscapes inhabited by beaver, suggest that beaver dispersal could vary significantly across their range. More generally, genetic structure can provide insights into the scale at which gene flow and dispersal occur, but genetic studies of beaver to date (Crawford et al. 2008b, Lizarralde et al. 2008) have not systematically addressed dispersal and population connectivity as a function of landscape structure.

The history and ecology of beaver in the Coast Range of Oregon, USA, are poorly understood. A review of historical exploration and trapping journals suggested that beaver in the Oregon Coast Range were common but not abundant during the European fur trade (Rainbolt 1999). Trapping in the Oregon Territory, and later Oregon, went unrestricted until 1893, and beaver trapping was prohibited statewide in 1899 (Kebbe 1960). Extirpation and reestablishment through translocation have occurred in most other parts of Oregon (Kebbe 1960). Yet because beaver in the Coast Range are less likely to build dams than those in other ecosystems, likely because of the narrow valley floors and constrained channel forms, characterizing their distribution and occupancy is difficult (Petro et al. 2018). This region is marked by abrupt, dissected watersheds, dense forests, and steep hillside slopes that transition sharply to valley floors or tidal reaches. Although extirpation was not verified, 732 beaver were released into the Oregon Coast Range between 1939 and 1951 (Oregon Department of Fish and Wildlife [ODFW], unpublished reports) as part of a program of $>3,000$ translocations intended to provide optimal distribution across the state (Hiller 2011). Sources came from within and outside of the Coast Range (ODFW, unpublished reports). Whether those beaver founded successful populations, displaced or interbred with resident beaver, or were excluded by resident beaver is unknown. Concomitant to the state beaver translocation program, there was no open trapping season for beaver. By the closure of the beaver translocation program in 1951, growing complaints of beaver conflict were reported across the state. In 1951, recreational trapping for beaver was reinstated in Oregon. From 1951 through 2015, numbers of beaver trapped annually through furbearer licenses in Oregon decreased from 15,347 to 1,220 (ODFW, unpublished reports). Despite a major decline in harvest, ODFW has witnessed no significant change in catch per unit effort over time (D. J. A. Broman, ODFW furbearer biologist, personal communication). On private lands, beaver fall within the management authority of the Oregon Department of Agriculture when they cause damage to private property (Oregon Revised Statute 610.002) and may be trapped without an ODFW license or permit.

Current interest in beaver in the region is high, given efforts to restore riparian systems (Weber et al. 2017, Silverman et al. 2019), improve overwinter stream habitat 
for coho salmon (Petro et al. 2015), reduce human-wildlife conflicts (Morzillo and Needham 2015, Petro et al. 2015), and promote recreational trapping. Translocation still occurs, but in Oregon, it must now be conducted in accordance with ODFW's Beaver Relocation Guidelines (ODFW 2017) and reported to ODFW district offices. Within the Oregon Coast Coho Evolutionarily Significant Unit (ESU), from 2009 to 2014, 99 nuisance beaver were translocated. The majority (77\%) were part of 2 research studies to evaluate the efficacy of ODFW's new Beaver Relocation Guidelines (Petro et al. 2015, ODFW 2017). Translocated beaver dispersed from release sites and paired with resident beaver on multiple occasions, but survival rates were low (Petro et al. 2015). Thus, although translocation has potential to influence genetic structure (Gille et al. 2019), in this case that influence may be lower than expected based on numbers of individuals moved.

Management requires a better understanding of the ability of beaver to disperse and colonize empty habitat, and the distances or landscapes over which a beaver, if translocated, is unlikely to return. We evaluated genetic structure and applied a landscape genetics approach to characterize landscape features that influence genetic flow for beaver in the Coast Range of Oregon. We hypothesized that watersheds would be the dominant landscape feature influencing beaver dispersal, with gene flow between watersheds less likely than gene flow within watersheds, because of behavioral tendencies to stay close to water. Because of the inherently hierarchical structure of streams and rivers, we considered watersheds defined at 3 scales: the basin (U.S. Geological Survey third-level classification), sub-basin (fourth-level), and for some analyses, major tributaries (fifth level). We also predicted that steeper slopes and greater distances to water would increase resistance to gene flow because of increased energetic costs of movement and exposure to predation by terrestrial mammals such as mountain lions. We considered an alternate possibility that legal and unsanctioned translocations of beaver during the twentieth and early twenty-first centuries in the region might obscure the effects of landscape on genetic structure.

\section{STUDY AREA}

We conducted research from April-September 2014 throughout 12 counties in western Oregon that occur within the Oregon Coast Coho ESU (Fig. 1). This ESU is approximately $2,848,012 \mathrm{ha}$ and is composed of coastal basins that are used to direct management for coho salmon, a federally threatened species. Forestry is the dominant land use in the area and forested ownership is $37 \%$ federal, $37 \%$ private, and $26 \%$ other (e.g., tribal, county, state). Major rivers in this area drain directly to the Pacific Ocean and rarely exceed $75 \mathrm{~km}$ in length. All but 1 of these river networks occur on the western slopes of the Oregon Coast Range (sea level to $1,300 \mathrm{~m})$. The exception is the Umpqua River Basin (Fig. 1A), whose headwaters rise from the western slopes of the Cascade Mountains (1,000-3,400 m; Wainwright and Weitkamp 2013). Terrain is generally steep with relatively dissected drainages. The Coast Range has a relatively mild climate with less temperature extremes than other parts of the state. Most of the study area experiences a warm-summer Mediterranean climate, characterized by warm $\left(18^{\circ} \mathrm{C}\right)$ summers (Jun-Aug) and mild $\left(3^{\circ} \mathrm{C}\right)$ wet winters with frequently cloudy skies (Dec-Feb). Precipitation is $81-240 \mathrm{~cm}$ each year and mostly occurs as rainfall, with flow regimes peaking during November-March. Average annual temperatures are $11-17^{\circ} \mathrm{C}$ (Western Regional Climate Center 2008). The forest overstory is dominated by Douglasfir (Pseudotsuga menziesii), western hemlock (Tsuga heterophylla), and red alder (Alnus rubra). Western redcedar (Thuja plicata) and bigleaf maple (Acer macrophyllum) are also common. Common understory vegetation includes huckleberry (Vaccinium spp.), Oregon-grape (Berberis spp.), salal (Gaultheria shallon), salmonberry (Rubus spectabilis), swordfern (Polystichum munitum), and vine maple (Acer circinatum; Cushman and McGarigal 2004). Known predators of beaver in the region include American black bear (Ursus americanus), bobcat (Lynx rufus), coyote (Canis latrans), mountain lion, and river otter (Lontra canadensis). Beaver populations are considered healthy and abundant throughout this area (Hiller 2011).

\section{METHODS}

\section{Animal Capture and DNA Collection}

We reviewed stream habitat survey reports and consulted with state and federal agency employees, landowners, watershed council members, and recreational trappers to identify potential beaver colony locations in western Oregon. Based on our previous beaver capture experience in this region (Petro et al. 2015), we also used map reconnaissance to identify potential trap sites. We livecaptured beaver using Hancock live traps (Hancock Trap Company, Custer, SD, USA) near active damming and foraging locations from 15 April-26 September 2014. We targeted all stream orders (first to seventh order) on private and public lands, and set traps in a manner that minimized the risk of drowning or capture of non-target species. At each location where we confirmed beaver activity, we set traps for 2 nights. We placed a small amount of commercial lure near each trap to increase attraction. We set traps before sunset and checked them daily within 2.5 hours of first light.

Upon locating a captured beaver, we moved the beaver to one side of the trap and exposed the tail. We disinfected a small area on the dorsal surface of the tail with isopropyl alcohol and collected a tissue sample using a sterilized disposable 3.0-mm biopsy punch pen (Miltex, York, PA, USA). Handling time was generally $<5$ minutes and we immediately released individuals at the capture site after processing. We identified re-captured individuals by the presence of scarring at the biopsy punch location and we immediately released them. We placed tissue samples in individual cryogenic vials filled with dimethyl sulfoxideethylenediaminetetraacetic acid (DMSO-EDTA) buffer saturated with sodium chloride. We then stored samples at 

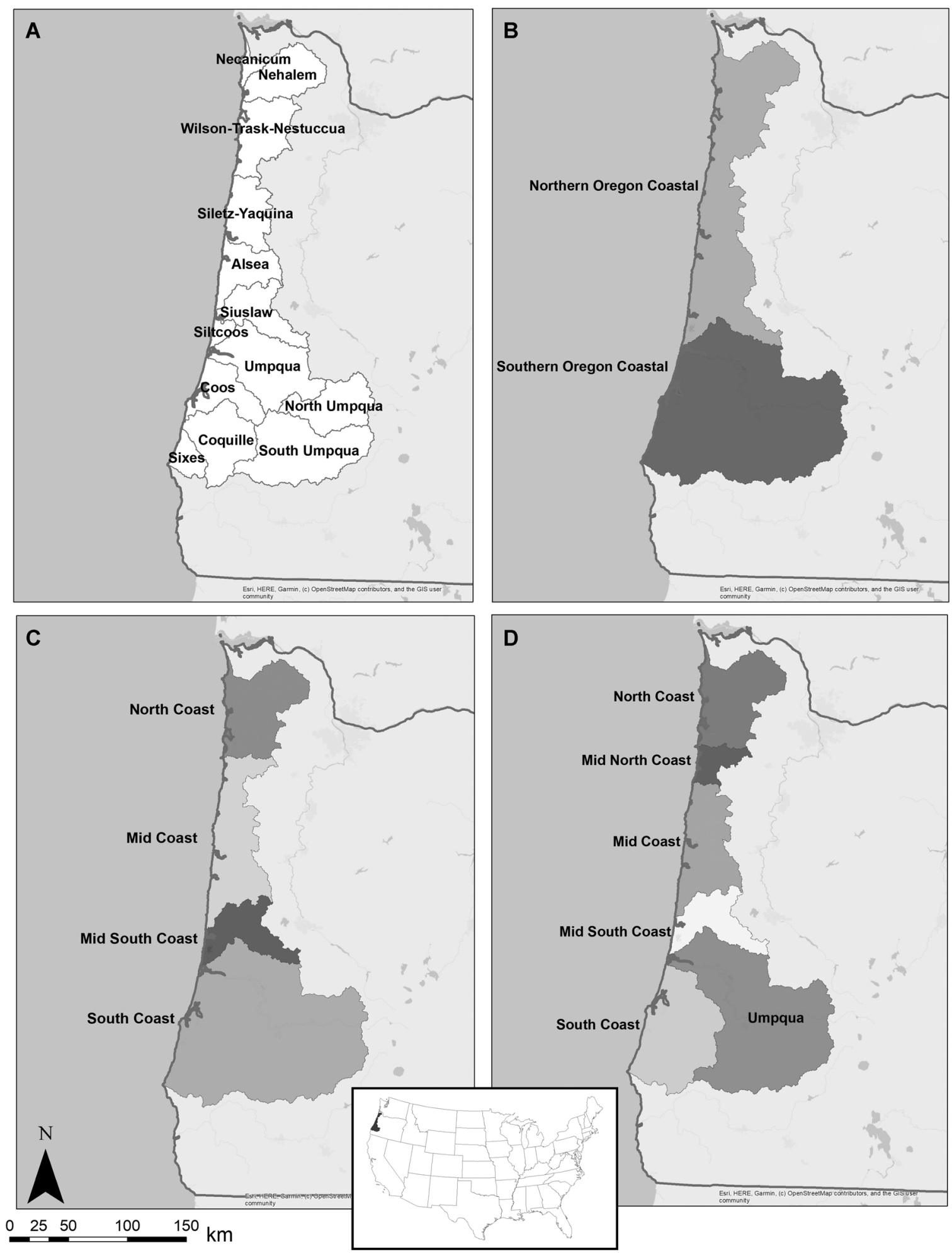

Figure 1. The study area in western Oregon, USA, comprising the Evolutionarily Significant Unit (ESU) for Oregon Coast coho, for evaluation of genetic structure of American beaver using samples collected in 2014. Geographical delineations for genetic analysis among groups of beaver in western Oregon are depicted, including population delineation models inferred from STRUCTURE analysis for different numbers of population clusters $(K)$, for A) sub-basin boundaries within the Oregon Coastal ESU, B) $K=2$, C) $K=4$, and D) $K=6$.

$-20^{\circ} \mathrm{C}$ until processing and analysis. All trapping and handling was approved by the United States Department of Agriculture, Animal and Plant Health Inspection Service, Wildlife Services, National Wildlife Research Center's Institutional Animal Care and Use Committee (QA-2261), and the Oregon Department of Fish and Wildlife (STP 077-14). We collected additional tissue samples from beaver that were legally trapped by lethal means for recreation or damage management, or opportunistically from those that had been road-killed in the study area. 


\section{Genotyping at Microsatellite Loci}

We extracted DNA from tissue samples using the DNeasy blood and tissue kit (Qiagen, Valencia, CA, USA) and genotyped samples at 10 microsatellite DNA loci previously developed for use in beaver, including loci $\mathrm{Cca} 4, \mathrm{Cca} 5, \mathrm{Cca} 8$, Cca9, Cca10, Cca13, Cca15, Cca18, and Cca19 (Crawford et al. 2008a) and Cca20 (Pelz-Serrano et al. 2009). We amplified microsatellite primers in 4 polymerase chain reactions (PCRs): 2 multiplexes and 2 single-locus amplifications (Table S1, available in Supporting Information). We amplified multiplex panels 1 and 2 in $10-\mu \mathrm{L}$ reactions consisting of 1x Qiagen Multiplex PCR master mix, $0.2-0.3 \mu \mathrm{M}$ of each primer (Table S1), $1 \mu \mathrm{g}$ of bovine serum albumin, and $1 \mu \mathrm{L}$ DNA; we brought reactions to volume with nuclease-free water. We labeled 1 primer from each pair with VIC, 6-FAM, PET, or NED (Applied Biosystems, Waltham, MA, USA). We ran multiplex reactions on a Bio-Rad C1000 or MyCycler thermocycler (Bio-Rad Laboratories, Hercules, CA) with the following cycling conditions: initial denaturation of 15 minutes at $95^{\circ} \mathrm{C}$, followed by 35 cycles of $95^{\circ} \mathrm{C}$ for 30 seconds, $60^{\circ} \mathrm{C}$ for 90 seconds, $72^{\circ} \mathrm{C}$ for 60 seconds, and a final elongation of 30 minutes at $60^{\circ} \mathrm{C}$. We also amplified single-locus panels 3 and 4 in $10-\mu \mathrm{L}$ reactions, but those reactions contained $1 \mathrm{x}$ magnesium-free buffer, $160 \mu \mathrm{M}$ of each deoxynucleoside triphosphate (dNTP), $1 \mu \mathrm{g}$ bovine serum albumin, $0.07 \mathrm{U}$ hot start Taq polymerase (Apex Bioresearch Products, Houston, TX, USA), $3 \mathrm{mM} \mathrm{MgCl}, 0.35 \mu \mathrm{M}$ of each primer, and $1 \mu \mathrm{L}$ of DNA; we brought reactions to volume with nuclease-free water. We ran single-locus PCRs on a Bio-Rad MyCycler thermocycler with the following cycling conditions: initial denaturation of 15 minutes at $95^{\circ} \mathrm{C}$, followed by 40 cycles of $95^{\circ} \mathrm{C}$ for 30 seconds, 45 seconds at $60^{\circ} \mathrm{C}$, and $72^{\circ} \mathrm{C}$ for 30 seconds, with a final elongation of 5 minutes at $72^{\circ} \mathrm{C}$.

We verified amplification on a $2 \%$ agarose gel with GelRed nucleic acid stain (Biotium, Fremont, CA), and diluted or concentrated amplicons depending on band brightness. After dilution, we combined all 4 PCR reactions (10 loci) for each sample in a single plate for genotyping analysis. We precipitated samples to remove unincorporated dNTPs and excess salts, and submitted samples to the Center for Genome Research and Biocomputing (Oregon State University, Corvallis, OR, USA) for fragment analysis on an ABI 3730 DNA Analyzer with GeneScan 500 LIZ sizing standard (Applied Biosystems). We scored genotypes using Genemapper version 4.1 (Applied Biosystems). To verify that each sample came from a unique individual, we ran each sample through the genetic matching program CERVUS version 3.07 (Kalinowski et al. 2007). We evaluated HardyWeinberg equilibrium (HWE) and linkage disequilibrium (LD) by population and locus. Defining appropriate populations for that analysis, however, was not straightforward in this system. Therefore, we tested for HWE and LD using multiple definitions of putative populations after evaluating population structure as described below.

\section{Mapping Historical Translocations}

We used ArcMap (version 10.7.1; Esri, Redlands, CA, USA) to map translocation events for any beaver released within the ESU based on records provided by ODFW. We used estimated locations for capture and release sites based on notes within those records, and recorded the number of beaver released and the year of the translocation. We used the resulting map to infer which areas within the ESU would likely have experienced the strongest potential influence of translocation on genetic structure, both as a function of number of translocations and distance of the source populations.

\section{Analysis of Genetic Structure}

We analyzed the genetic structure of beaver across the study area using the Bayesian clustering program STRUCTURE version 2.3.4 (Pritchard et al. 2000), which determined the most likely number of genetic clusters and each individual's probability of belonging to each cluster on the basis of allele frequencies. We included a burn-in period of 500,000 steps, then estimated parameters based on a run of $1,000,000$ additional steps, assuming admixture and correlated allele frequencies among populations. We did not use presumed population identity as a prior, nor did we initiate runs based on sampling location. We allowed the number of clusters $(K)$ to range from 1 to 10 , with 10 iterations for each value of $K$. We used inspection of the mean likelihood curves and the $\Delta K$ method of Evanno et al. (2005), implemented in STRUCTURE HARVESTER (Earl and von Holdt 2012), to identify the most probable number of clusters. We estimated average individual assignment probabilities to each cluster across iterations using CLUMPP (Jakobsson and Rosenberg 2007). Because the potential presence of closely related individuals can bias these analyses, we repeated the STRUCTURE analysis after identifying and removing closely related individuals as follows. We defined close relationships for this analysis as those where Lynch and Ritland's (1999) $r>0.4$. We chose that threshold to detect full-sibling or parent-offspring pairs $(r \sim 0.5)$, while allowing for some error in the relatedness estimates. Because relatedness estimates require accurate allele frequency estimates for reference, but allele frequencies can vary within a study area owing to genetic structure, we selected the largest supported value of $K$ from the initial STRUCTURE analysis (see Results) and estimated related individuals within each of those clusters using program COANCESTRY (version 1.0.1.8; Wang 2010). Subsequently, because additional genetic structure likely was present within those clusters, leading to some potential spurious identification of pairs as closely related, we examined the frequency distribution of geographic distances among related pairs and selected a spatial scale at which most closely related individuals were apparent in our sample. Then, we eliminated 1 of each dyad of closely related individuals within that threshold geographic distance and repeated the STRUCTURE analysis to examine consistency of results.

\section{Isolation by Distance and Dispersal Distance}

One of the most common patterns observed in landscape genetic studies is isolation by distance (Wright 1943), in which geographically distant individuals are more genetically different. We tested for this pattern by examining the 
relationship between inter-individual Euclidean distance and inter-individual genetic distance, using a Mantel test (Mantel 1967) as an exploratory technique prior to landscape genetic analysis, although this test is affected by spatial autocorrelation and is best used in systems with mutation-migration-drift equilibrium (Guillot and Rousset 2013). We calculated genetic distance as the Bray-Curtis distance (BC), which is equal to 1 minus the proportion of alleles shared between individuals (Bray and Curtis 1957). We estimated Pearson correlation between BC distance and both geographic distance and $\log$ (geographic distance) using the ecodist package (version 2.0.3; Goslee and Urban 2007) in $\mathrm{R}$ (version 4.0.0; $\mathrm{R}$ Core Team 2018). Calculations involving $\mathrm{BC}$ used all 10 loci because this statistic is modelfree and does not assume HWE.

We generated a Mantel correlogram (Borcard and Legendre 2012) evaluating the correlation between genetic distance (BC) and geographic (Euclidean) distance over distance classes. We used ecodist and evaluated correlation for 15 evenly divided distance classes over the $350-\mathrm{km}$ maximum distance between samples; sample sizes per distance class varied from 514-10,492, although all but the largest distance class included $>1,100$ comparisons. Akin to the concept of genetic neighborhood distance (Wright 1946), this approach evaluates the distances over which genetic distance is correlated with geographic distance, compared to the genetic distance between samples chosen at random. We interpreted the distances at which we observed positive correlation as indicative of the scale at which dispersal occurs (McCormick et al. 2016), although true average dispersal distances are likely less because genes can spread across the landscape through the movements of multiple individuals across multiple generations.

\section{Landscape Resistance Modeling}

We tested a suite of landscape resistance models to determine which landscape variables potentially influence gene flow among beaver in the study area. Landscape resistance models typically take the form of raster surfaces in which the value of each cell represents the cost of dispersing through that cell as a function of its landscape attributes. An optimal landscape resistance model is identified by testing the strength of the relationship between genetic distance (i.e., how genetically dissimilar 2 individuals are) versus cost distance (i.e., the cumulative resistance-weighted distance between individuals) for a variety of candidate models; the optimal model is that for which cost distance explains the most variation in genetic distance.

Thus, the basic steps in the analysis were 1) generate a matrix of genetic distances between individuals, 2) develop a set of candidate landscape resistance models reflecting different relationships between landscape variables and resistance to gene flow, 3) generate a matrix of cost distances between individuals for each candidate resistance model, and 4) use a modified linear regression approach to determine which candidate resistance model best explained genetic distances for each landscape variable. We tested the effects of 4 variables on landscape resistance. We included distance to nearest water feature because beaver may avoid dispersing through areas that are a long way from water features; slope of terrain because dispersing through highly sloped terrain may be energetically costly for beaver; thirdlevel basin boundaries (Seaber et al. 1987) because beaver may prefer to disperse within a major drainage basin rather than dispersing between basins, which would require movement away from water sources and through steep terrain to cross basin boundaries; and fourth-level sub-basin boundaries (Seaber et al. 1987), which is similar to thirdlevel basin boundaries but assumes that sub-basins are more relevant to beaver dispersal behavior than are basins.

We converted all geospatial variables to raster surfaces with 3-arcsecond $(\sim 100 \mathrm{~m})$ cell resolution. For basin and sub-basin boundary layers, we buffered boundary line features in vector layers by $100 \mathrm{~m}$ on each side to ensure that there were no gaps in the resulting raster layers that could produce inaccurate cost distances. In addition, we created a raster with all cell values equal to 1 to serve as a null model of isolation by distance. For each candidate resistance model, we calculated cumulative cost distances between individuals along the least-cost path (LCP; Adriaensen et al. 2003) using the gdistance package (version 1.1-9; van Etten 2017) in R. The LCP model of dispersal assumes that individuals have essentially perfect knowledge of the optimal dispersal routes between locations. For the continuous landscape variables (slope and distance to water), we used the following equation to create a set of candidate resistance models reflecting different possible relationships between these landscape variables and resistance:

$$
r=\frac{x^{\alpha}}{x_{\max }^{\alpha}} \times\left(r_{\max }-1\right)+1,
$$

where resistance $(r)$ of a given cell varies between 1 and a user-defined maximum resistance value $\left(r_{\max }\right)$ as a function of the landscape variable value $(x)$ in that cell, the maximum value of the landscape variable within the study area $\left(x_{\max }\right)$, and an exponent $(\alpha)$ that determines the shape of the curve (Fig. S1, available in Supporting Information). We tested all combinations of $3 r_{\max }$ values $(10,50$, and 100) and $3 \alpha$ values $(0.25,1$, and 4$)$ for 9 candidate models each for slope and distance to water. For the categorical landscape variables (basin, sub-basin boundaries), we assigned a high resistance value $(100,1,000$, or 10,000$)$ to cells delineating the basin or sub-basin boundaries and a resistance of 1 to all cells not on those boundaries, resulting in 3 candidate surfaces for each of these variables.

We identified the optimal resistance model for each landscape variable using a pseudo-bootstrapping approach (Worthington Wilmer et al. 2008) that is similar to a traditional linear regression; it accounts for the non-independence of pairwise data by randomly sampling independent subsets of pairs from the dataset. For each of 10,000 random samples, we fitted a linear regression model of genetic distance (BC) as a function of cost distance for each candidate resistance model and calculated Akaike's Information Criterion 
(AIC). We excluded all individual pairs separated by distances greater than the neighborhood distance $(85 \mathrm{~km}$, see below) because these data did not contribute useful information on the relationship between gene flow and environmental characteristics owing to very long distances between individuals; thus, the maximum number of pairs in each random sample varied but was less than the theoretical maximum of half the number of individuals. We used the median Akaike weight of each resistance model across the 10,000 random samples as our model selection criterion, and calculated the median $R^{2}$ for each model as a measure of explanatory power. We included a Euclidean distance model (i.e., all cells have resistance of 1 ) in the candidate set for each variable as a null model of isolation by distance. We logtransformed cost distances to improve linearity.

Because initial results indicated negligible effects of all tested landscape variables on gene flow, we did not pursue a multivariate optimization in which effects of multiple variables would be combined in a single resistance model, as is typically done in landscape genetic studies. We explored one possible reason for the lack of findings from the landscape resistance modeling by repeating a portion of the above analysis using an alternative model of dispersal: circuit theory (McRae 2006). Circuit theory assumes that individuals exhibit random walk behavior when dispersing and have no knowledge of optimal dispersal routes. Circuit theory and LCPs represent 2 extremes along a gradient of possible dispersal behaviors, and for many animals it is not obvious which is more applicable. We used Circuitscape version 4.0.5 (Shah and McRae 2008) to calculate cost distances associated with the top-performing candidate model for each variable from the LCP-based analysis, plus the Euclidean distance surface, then repeated the pseudobootstrapping analysis and calculated median $R^{2}$ for these models with circuit theory-based responses. We compared model $R^{2}$ values from the LCP- and circuit theory-based analyses to determine whether circuit theory explained more variation in genetic distance among individuals, and whether a full analysis using circuit theory was warranted.

\section{Genetic Differentiation}

To consider how genetic variation was distributed on the landscape, in addition to the landscape genetic analyses, we organized beaver samples into analytical groups to evaluate which STRUCTURE-identified clusters or watershed designations (Fig. 1) best corresponded with the variation in genetic structure we detected. This made it possible to examine for discontinuities among nearby watersheds and to consider the degree of differentiation across the study area. After conducting the STRUCTURE analysis, for each value of $K$ determined to reflect meaningful partitions in the data, we reviewed the intersection of individual assignments with watersheds (Fig. 2). Next, we grouped watersheds according to the predominating differences in cluster assignments and grouped individuals within those watersheds accordingly for further analysis. Thus, rather than assigning individuals to analytical groups solely based on cluster membership, we used geographical regions broadly distinguished by the multiscale STRUCTURE analyses to group individuals. We evaluated 4 primary models of population delineation: 3 hierarchical clustering models suggested by STRUCTURE analyses, and 1 using groups based on fourth-level sub-basins (Seaber et al. 1987), albeit combining several closely associated sub-basins where sample sizes were $<6$. Then, for each model of population delineation, we estimated HWE and LD by locus and by population using GENEPOP (Rousset 2008). While evaluating HWE, we also evaluated a fifth model representing watersheds of individual major tributaries as spatial units. We employed the global tests for heterozygote deficit and excess using default settings in GENEPOP, testing across populations and across loci, and used simple Bonferroni correction because the numbers of populations and loci were relatively small. Further, we used GENEPOP to test for genotypic disequilibrium for each locus pair across all populations for each model of population delineation.

After removing 1 locus that showed persistent HWE violations (see Results), we estimated genetic distance (population pairwise $F_{\mathrm{ST}}$ ) among groups using GENEPOP (Rousset 2008). Next, likewise with the 9 loci not showing persistent violations of HWE, we used Arlequin version 3.11 (Excoffier et al. 2005) to conduct analysis of molecular variance (AMOVA) for each of the 4 primary models of population delineation, evaluating the proportion of variation distributed within individuals, among individuals within groups, and among groups. We used pairwise differences, 1,000 permutations, and averaged results across loci.

Finally, we performed 4 principal component analyses (PCA) on the entire sample dataset, in which we categorized individuals according to each population delineation model and evaluated how well partitioning of genetic variance in a model-free manner reflected the divisions in each model. We used the adegenet $R$ package (version 2.0.0; Jombart 2008) to conduct and visualize the PCAs; we replaced missing data in the genotypes with the average of allele sizes for these analyses (Jombart 2008). Because PCA is a model-free approach and does not require assuming HWE, we used all 10 loci for PCA analysis. We plotted results including ellipses representing $95 \%$ probabilities based on a multivariate t-distribution (Fox and Weisberg 2011).

\section{RESULTS}

After removing 1 roadkill sample that had previously been livetrapped, our genetic dataset consisted of 291 individuals (232 live-captured over 917 trap nights, 1 road-killed, 58 from recreational trappers) genotyped at 10 microsatellite loci. Genotyping data were $99 \%$ complete; 24 samples were missing data at 1 locus, 2 samples at 2 loci, and 1 sample at 3 loci.

\section{Mapping Historical Translocations}

We identified 101 complete events (i.e., where records identified capture and release sites) representing 342 beaver translocated to sites within the ESU. Translocations occurred from 1940-2014, with 71\% of these occurring prior to 1951 . Translocations moved an average of 3 beaver (range $=1-11$ ) per event and $70 \%$ of capture sites were located outside the 
A

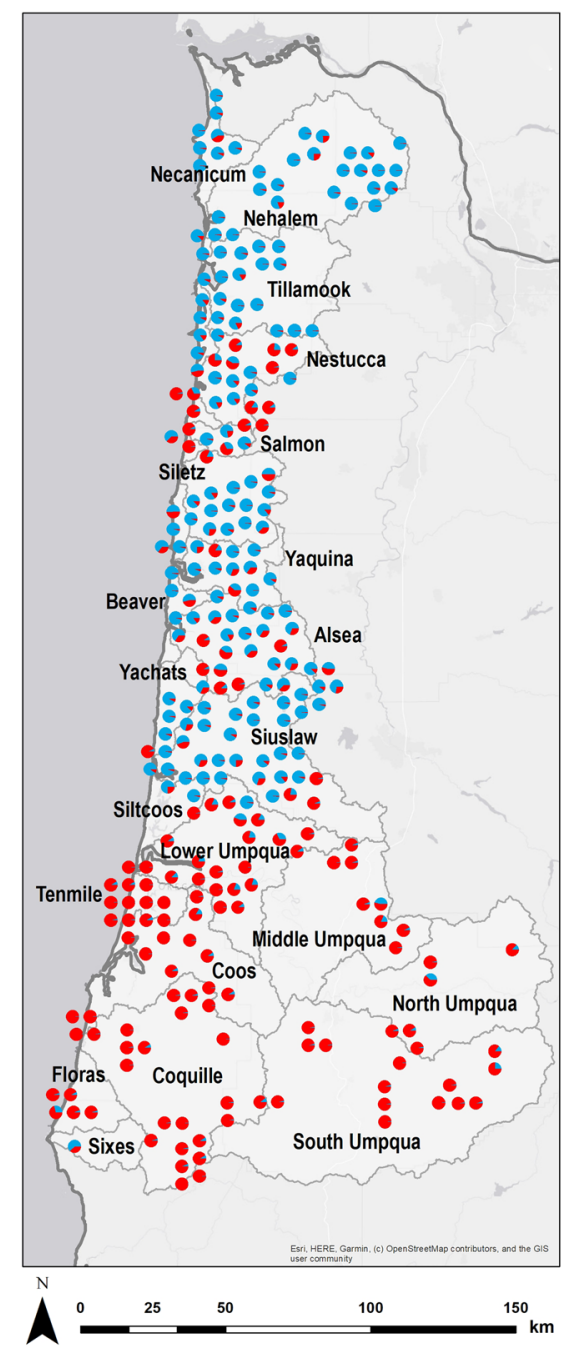

B

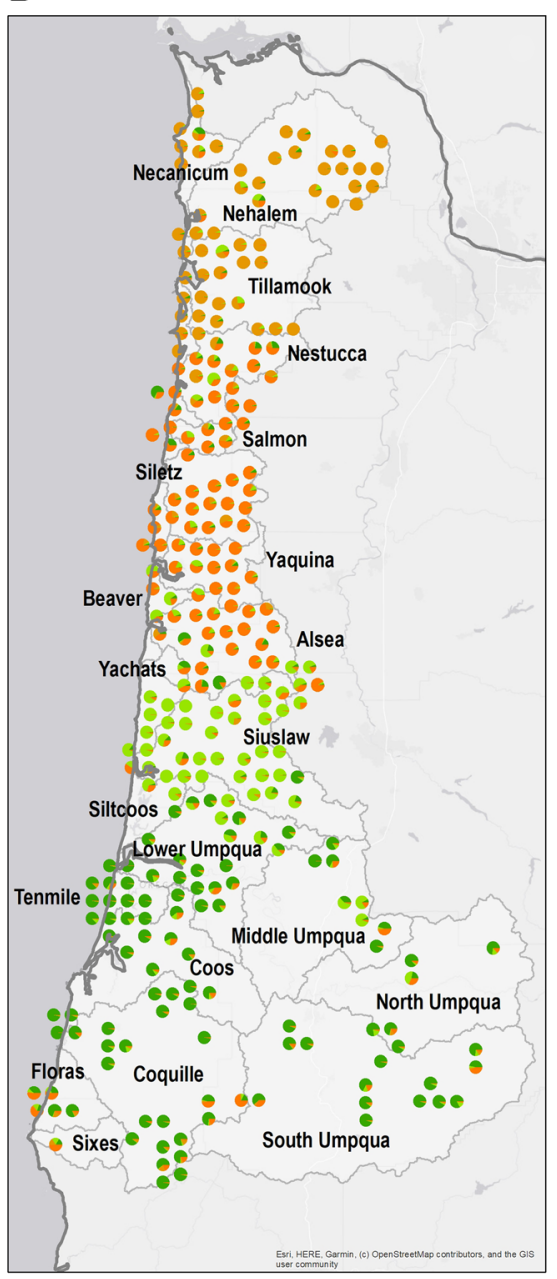

C

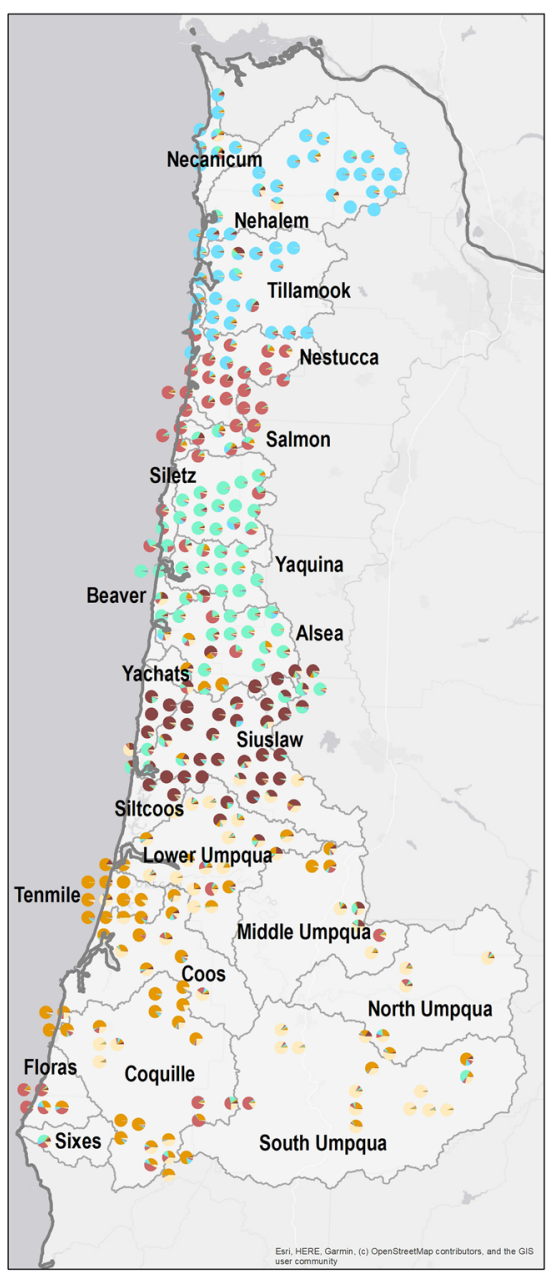

Figure 2. Cluster assignment probabilities from STRUCTURE analysis of 291 American beaver sampled in 2014 in western Oregon, USA, assuming the number of clusters $(K)$ was A) $K=2$, B) $K=4$, and C) $K=6$. Each circle represents a sampled individual. Colors within circles represent proportional assignment probabilities to clusters. Partial assignments at the southern edge of the study area may reflect influence from other clusters outside the study area, rather than affinity to that particular cluster.

ESU. We determined translocated beaver were moved an average of $131.0 \mathrm{~km} \quad$ (range $=10.3-382.6$ ) based on Euclidean distances measured between capture and release sites. Release sites (Fig. 3) were concentrated within the combined Wilson-Trask-Nestucca watersheds, the Alsea watershed, and Coquille, Umpqua, North Umpqua, and South Umpqua, collectively considered South Coast or Umpqua and South Coast (Fig. 1). The combined Umpqua and South Coast regions received the most translocated beaver and the largest number of translocations from a distant source population (central Oregon), resulting in the greatest potential effect of translocation on genetic structure in that region (Fig. 3), assuming that translocations with complete records were a representative sample of the 732 reported (ODFW, unpublished reports).

\section{Genetic Structure}

The STRUCTURE analysis produced a likelihood curve that increased smoothly to a plateau at $K=6$ (Fig. S2, available in Supporting Information). The most likely number of clusters (i.e., highest $\Delta K$ value) was 2 (Fig. S3, available in Supporting Information), and most individuals were assigned strongly ( $>90 \%$ probability) to 1 cluster when $K=2$ (Fig. 2A; Fig. S4, available in Supporting Information). Individual assignment probabilities at $K=2$ suggested a major split between individuals in the Northern Oregon Coastal basin (including all sub-basins from the Siuslaw north) versus individuals in the Southern Oregon Coast basin (including all sub-basins from the Lower Umpqua south; Fig. 2A). Some individuals, however, particularly in the Alsea, Salmon, and Nestucca drainages, assigned strongly to a different cluster than would be expected based on their sampling location (Fig. 2A).

We also found evidence for hierarchical genetic structure within the 2 primary clusters. We observed smaller peaks in $\Delta K$ at $K=4$ and $K=6$ (Fig. S3). The northern $K=2$ cluster was further split into 3 clusters when $K=4$ (Fig. 2B) and 4 clusters when $K=6$ (Fig. 2C). At $K=6$, the southern $K=2$ 


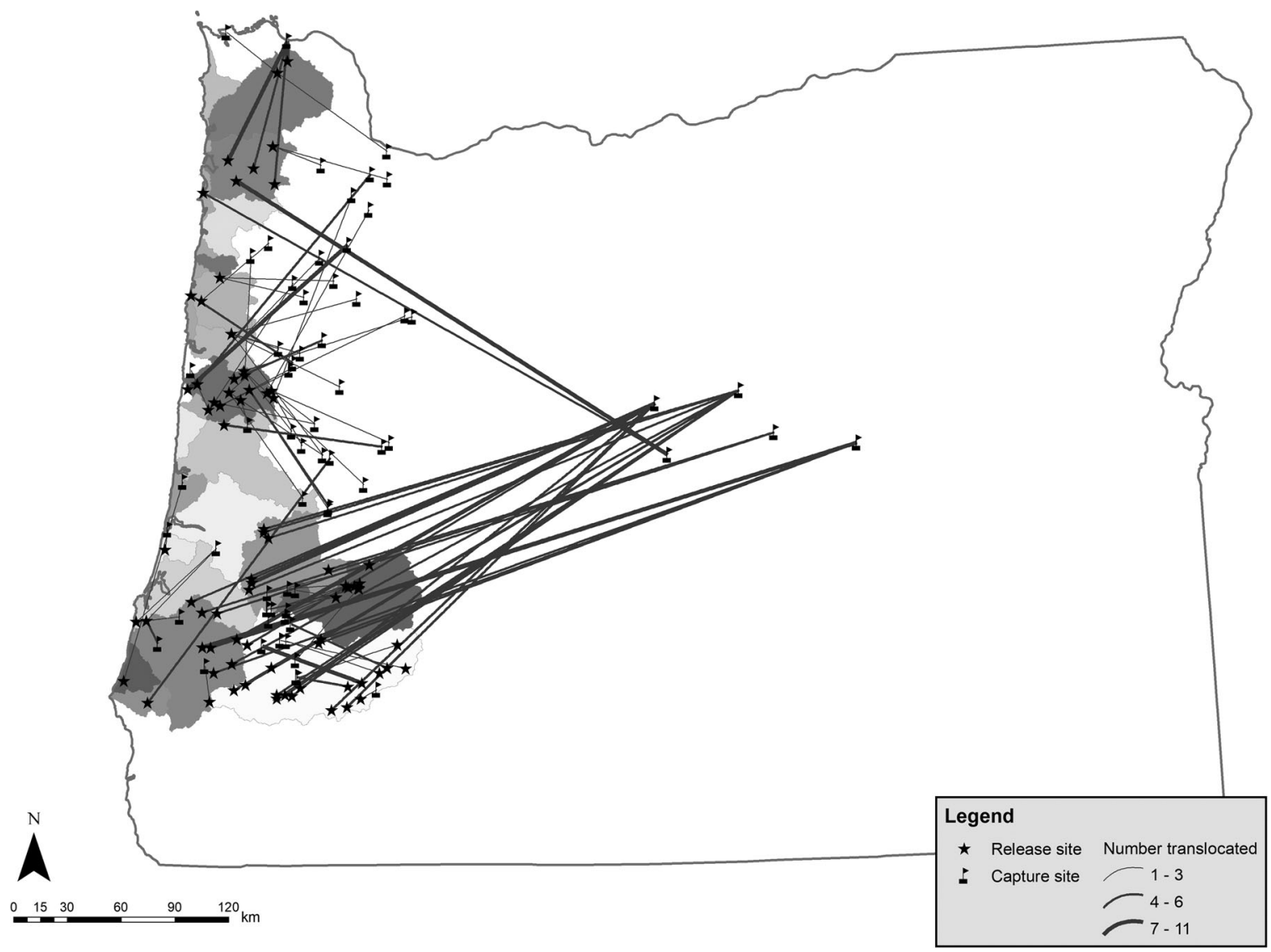

Figure 3. Records of translocations for American beaver into or within the study area in western Oregon, USA, 1940-2014, with major tributary (fifth level) watersheds depicted within the study area. Only translocations with records of capture and release sites are included ( $n=101$ translocations, 342 beaver); $70 \%$ of translocations occurred prior to 1951.

cluster was further split into 2 clusters with considerable mixed ancestry (Fig. 2C). We also observed a number of individuals sampled at the very southern extent of the study area with partial assignment to northern clusters; that likely represented the influence of other clusters outside the study area, rather than true assignment to northern clusters (Figs. 2 and S4). Individuals assigning strongly to multiple clusters were more common in the results for $K=4$ and $K=6$ (Figs. 2 and S4).

A

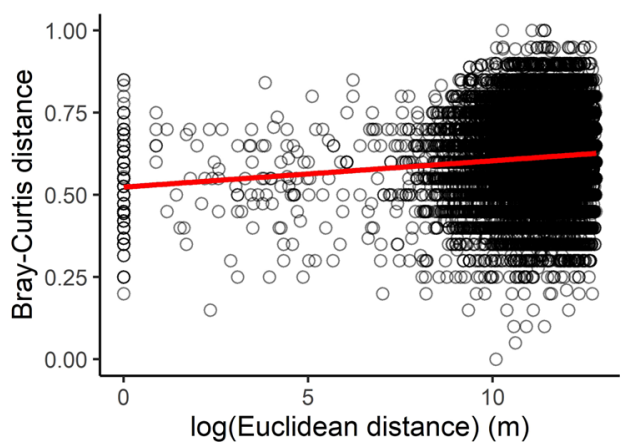

After screening for individuals related at $r>0.4$ within the $K=6$ clusters using the 9 loci in HWE (see below), we determined that 38 of 77 closely related pairs were sampled $<1 \mathrm{~km}$ apart; 95\% (73) were $<55 \mathrm{~km}$ apart (range $=$ $<0.01-77.5 \mathrm{~km}, \operatorname{median}=1.0 \mathrm{~km}, \bar{x}=14.6 \pm 2.3[\mathrm{SE}] \mathrm{km}$, $n=77$; Fig. S5, available in Supporting Information). Removing 1 of each pair and repeating the STRUCTURE analysis also strongly supported $K=6$ (data not shown), so we retained the full dataset for additional analyses.
B

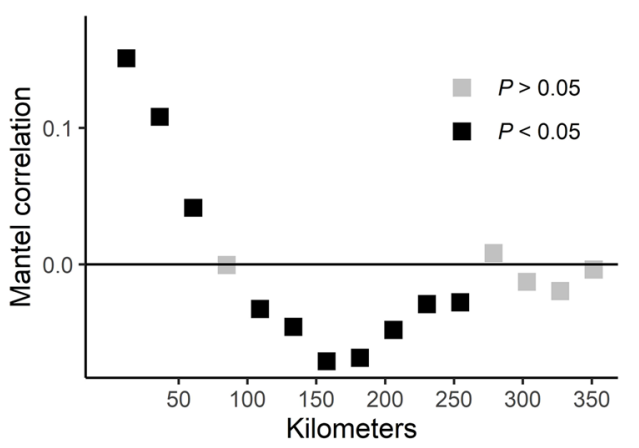

Figure 4. Individual genetic differences among 291 American beaver sampled in 2014 in western Oregon, USA, including A) genetic distance (Bray-Curtis) regressed on log of distance between sampling locations, and B) Mantel correlogram showing correlation of genetic distance and Euclidean distance between individuals over distance classes ranging from $0-350 \mathrm{~km}$. Genetic similarity was greater than expected by chance at distances $<61 \mathrm{~km}$, and lower at $109-254 \mathrm{~km}$. 
Table 1. Optimized resistance models for landscape variables included in landscape genetic analyses of American beaver sampled in 2014 in western Oregon, USA.

\begin{tabular}{lccc}
\hline & & \multicolumn{2}{c}{ Median $\boldsymbol{R}^{\mathbf{2}}$} \\
\cline { 3 - 4 } Landscape variable & Optimal resistance model & $\mathbf{L C P}^{\mathbf{a}}$ & Circuit $^{\mathbf{b}}$ \\
\hline Distance to water & $r_{\max }{ }^{\mathrm{c}}=100, \alpha^{\mathrm{d}}=4$ & 0.053 & 0.040 \\
$\begin{array}{l}\text { Slope } \\
\text { Basin boundaries }\end{array}$ & $\begin{array}{c}r_{\max }=50, \alpha=4 \\
\text { boundary cell } \\
\text { resistance }=1,000 \\
\text { boundary cell }\end{array}$ & 0.054 & 0.042 \\
$\quad \begin{array}{c}\text { Sub-basin } \\
\text { boundaries }\end{array}$ & $\begin{array}{c}\text { resistance }=1,000 \\
\text { Euclidean distance }\end{array}$ & 0.062 & 0.050 \\
\hline
\end{tabular}

${ }^{a}$ Median $R^{2}$ for model in which we calculated cost distance using leastcost path method.

${ }^{\mathrm{b}}$ Median $R^{2}$ for model in which we calculated cost distance using circuit theory method.

${ }^{\mathrm{c}}$ User-defined maximum resistance value employed in calculating resistance as a function of landscape variable values (eq. 1).

${ }^{\mathrm{d}}$ User-defined exponent that determines the shape of the curvilinear relationship between resistance and landscape variables (distance to water and slope, eq. 1).

\section{Isolation by Distance and Dispersal Distance}

We observed a weak, positive correlation between genetic distance $(\mathrm{BC})$ and geographic distance in the dataset $(r=0.16, P=0.001)$. As predicted by population genetic theory (Slatkin 1995), this relationship was more linear when geographic distance was log-transformed $(r=0.21$, $P=0.001$; Fig. 4A). The Mantel correlogram showed positive correlation between genetic distance and geographic distance persisting through the $61-\mathrm{km}$ distance class; individual genetic differentiation was no different from random at $85 \mathrm{~km}$ but was negatively correlated with distance from $109-254 \mathrm{~km}$ (Fig. 4B).

\section{Landscape Resistance Modeling}

The explanatory power of all landscape resistance models tested was very low (Table 1 ). Cost distance calculated using the LCP method explained $<7 \%$ of the variation in genetic distance among individuals. For all 4 resistance variables, $\geq 1$ candidate model had a higher median Akaike weight than the null (Euclidean distance) model. These optimal univariate models, however, explained $<1 \%$ more genetic distance variation beyond the Euclidean distance model. Alternative models using cost distances based on circuit theory explained slightly less variation in genetic distance than those based on LCP (Table 1).

\section{Genetic Differentiation}

Global HWE tests across different definitions of populations $(K=2,4,6$; sub-basins, and major tributary watersheds) showed no evidence of heterozygote excess at any locus or in any population ( $P>0.05$ in all cases). Tests for heterozygote deficit showed that many populations or loci were out of HWE for the population defined on the basis of $K=2,4$, and 6; tests based on the sub-basin and major tributary watersheds showed diminishing proportions of populations or loci with heterozygote deficit (Table 2). At the finest level of differentiation (major tributary [fifthlevel] watersheds), only the Siuslaw watershed population and the Cca4 locus showed heterozygote deficit (Table 2). Tests for genotypic (linkage) disequilibrium showed significant (sequential Bonferroni correction, $\alpha=0.05$ ) disequilibrium for 1 locus pair for each population delineation model (data not shown); however, the loci involved differed in each case, suggesting no consistent linkage disequilibrium existed among the loci we employed.

Geographically grouping the dataset using the 1 major partition identified with program STRUCTURE $(K=2)$ resulted in a weak estimate of genetic structure between the geographic interpretation of those clusters (Figs. 1 and 2; $F_{\mathrm{ST}}=0.045$, using the 9 loci remaining after removing Cca4 for persistent violations of $\mathrm{HWE}$ ). The $K=4$ population delineation model demonstrated the greatest differentiation $\left(F_{\mathrm{ST}}=0.107\right)$ between the mid-south coast cluster and the north coast cluster, followed by the mid-south coast and south coast clusters $\left(F_{\mathrm{ST}}=0.092\right.$; Table S2, available in Supporting Information). The mid-south coast cluster and the south coast cluster showed the greatest level of differentiation within the STRUCTURE population assignment of $K=6\left(F_{\mathrm{ST}}=0.125\right)$, followed by north coast and midsouth coast $\left(F_{\mathrm{ST}}=0.108\right.$; Fig. 1 ; Table S3, available in Supporting Information). The sub-basin (fourth level) population delineation model provided even higher estimates of genetic differentiation among some clusters, including some comparisons among the most distant clusters (e.g., $F_{\mathrm{ST}}=0.192$ between Necanicum and North Umpqua; Fig. 1; Table 3), although we also observed high values between less distant pairs (e.g., $F_{\mathrm{ST}}=0.150$ between Necanicum and North Umpqua; Fig. 1; Table 3). Evaluation of these population delineation models using AMOVA (9 loci) showed that the amount of variation

Table 2. Tests for Hardy-Weinburg equilibrium of genetic samples of American beaver collected in 2014 in western Oregon, USA; we conducted tests across populations (defined according to genetic clusters $[K]$ and by topography) and across 10 microsatellite loci, using global tests for heterozygote deficit with and without Bonferroni corrections for multiple comparisons for tests by population.

\begin{tabular}{lcccc}
\hline $\begin{array}{l}\text { Population } \\
\text { delineation model }\end{array}$ & $\begin{array}{c}\text { Number of } \\
\text { populations }\end{array}$ & $\begin{array}{c}\text { Proportion of populations } \\
\text { with heterozygote } \\
\text { deficit }(\boldsymbol{P}<\mathbf{0 . 0 5})\end{array}$ & $\begin{array}{c}\text { Proportion of populations with } \\
\text { heterozygote deficit using } \\
\text { Bonferroni correction (critical } \\
\text { value of } \boldsymbol{P}, \boldsymbol{\alpha}=\mathbf{0 . 0 5})\end{array}$ & $\begin{array}{c}\text { Number of loci showing } \\
\text { heterozygote deficit }(\text { Bonferroni } \\
\text { corrected } \boldsymbol{\alpha}=\mathbf{0 . 0 5}, \boldsymbol{P}<\mathbf{0 . 0 0 5})\end{array}$ \\
\hline$K=2$ & 2 & 1.0 & $1.0(P<0.025)$ & 5 \\
$K=4$ & 4 & 1.0 & $1.0(P<0.013)$ & 4 \\
$K=6$ & 6 & 0.83 & $0.33(P<0.008)$ & 2 \\
Sub-basins & 10 & 0.50 & $0.20(P<0.003)$ & 1 \\
$\begin{array}{l}\text { Major tributary } \\
\text { watersheds }\end{array}$ & 15 & 0.20 & $0.07(P<0.003)$ & \\
\hline
\end{tabular}


Table 3. Genetic structure $\left(F_{\mathrm{ST}}\right)$ estimates and sample sizes for populations of American beaver in western Oregon, USA, sampled in 2014. We defined populations based on United States Geological Survey (USGS) sub-basin (fourth level) watersheds, although we combined New River, Floras, and Sixes subbasins because of proximity and low within-sub-basin sample size. Genetic structure estimates were based on 9 microsatellite loci (we removed Cca4 for this analysis because of persistent violations of Hardy-Weinberg equilibrium).

\begin{tabular}{|c|c|c|c|c|c|c|c|c|c|c|c|c|}
\hline Population & Alsea & Coos & Coquille & Umpqua & Necanicum & Nehalem & $S Y^{a}$ & WTN $^{\mathbf{b}}$ & Siuslaw & South Umpqua & SNRF $^{c}$ & Sample size \\
\hline Alsea & & & & & & & & & & & & 31 \\
\hline Coos & 0.097 & & & & & & & & & & & 23 \\
\hline Coquille & 0.106 & 0.057 & & & & & & & & & & 22 \\
\hline Necanicum & 0.098 & 0.118 & 0.108 & 0.120 & & & & & & & & 8 \\
\hline Nehalem & 0.115 & 0.131 & 0.098 & 0.111 & 0.045 & & & & & & & 23 \\
\hline $\mathrm{SY}^{\mathrm{a}}$ & 0.033 & 0.112 & 0.111 & 0.080 & 0.110 & 0.084 & & & & & & 40 \\
\hline South Umpqua & 0.090 & 0.049 & 0.071 & 0.033 & 0.146 & 0.097 & 0.074 & 0.065 & 0.097 & & & 15 \\
\hline $\mathrm{SNRF}^{\mathrm{c}}$ & 0.104 & 0.097 & 0.090 & 0.109 & 0.153 & 0.159 & 0.122 & 0.088 & 0.162 & 0.137 & & 6 \\
\hline North Umpqua & 0.122 & 0.073 & 0.130 & 0.057 & 0.192 & 0.116 & 0.094 & 0.087 & 0.103 & 0.012 & 0.181 & 6 \\
\hline
\end{tabular}

${ }^{a}$ Siletz and Yaquina watersheds were combined by USGS at this level of classification.

${ }^{\mathrm{b}}$ Wilson, Trask, and Nestucca watersheds were combined by USGS at this level of classification.

${ }^{c}$ Sixes, New River, and Floras watersheds were combined because of proximity and small within-sub-basin sample size.

explained among populations increased with the number of geographically assigned clusters $(5 \%$ for $K=2,7 \%$ for $K=4$, $8 \%$ for $K=6$, and $9 \%$ for groups defined at the sub-basin level). Variation among individuals decreased as the number of groups increased ( $10 \%$ for $K=2,7 \%$ for $K=4,6 \%$ for $K=6$, and sub-basin groups $=5 \%$ ). The percentage of variation explained within individuals was similar for all groups, ranging from $85 \%(K=2)$ to $87 \%$ (sub-basins).

Principal component analyses of the 4 population delineation models using all 10 loci suggested that genetic differentiation across the study area was moderate, with only $6.9 \%$ of the variation explained on the first 2 axes. The primary division appeared between the South Coast and more northern samples (Fig. 5A), although differentiation corresponding with the $K=4$ population delineation also was apparent (Fig. 5B). Population delineation models with more clusters ( $K=6$, not shown; and sub-basin, Fig. 5C) were not reflected in the first 2 axes of variation.

\section{DISCUSSION}

There was evidence of genetic structure and isolation by distance at multiple levels within the Coast Range of Oregon for beaver, but landscape genetic analyses did not support our hypotheses that slope, distance to water, or basin and sub-basin boundaries influenced individual genetic differentiation, and by inference, dispersal. Major watersheds (third- and fourth-level), however, aligned with breaks in genetic structure of beaver along the Coast Range. This result was apparent in genetic clustering as ascertained by assignment tests, AMOVA tests, and PCA. Those findings supported our hypothesis that gene flow was more common within than between watersheds. Some gene flow
A

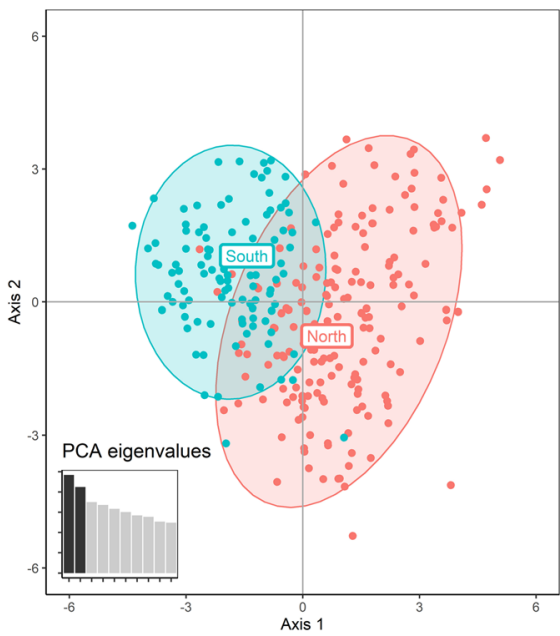

B

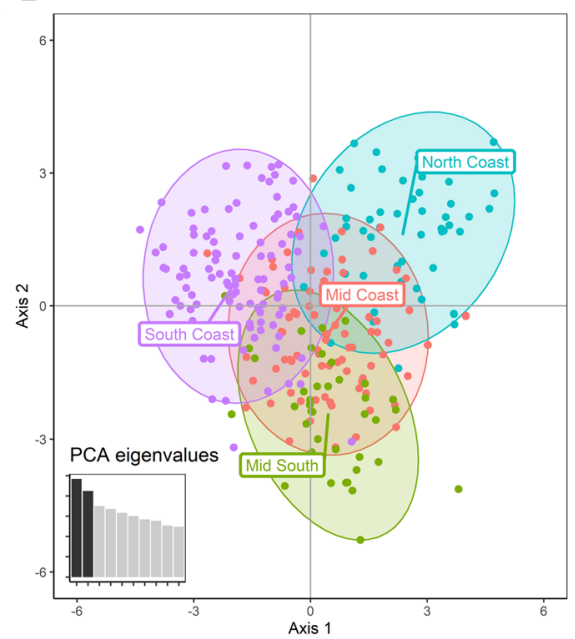

C

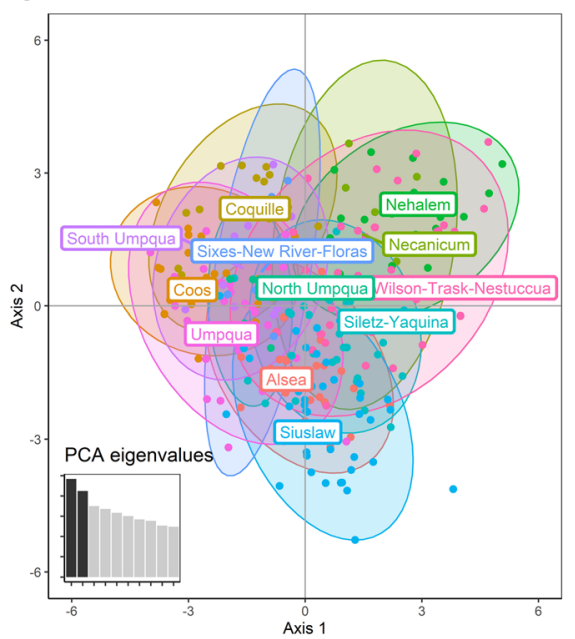

Figure 5. Plots of the first 2 axes from principal components analysis (PCA) of genetic samples of American beaver collected in 2014 in western Oregon, USA, with individuals grouped according to A) northern and southern clusters $(K=2), \mathrm{B})$ northern, mid, mid-south, and southern clusters $(K=4)$, and $\mathrm{C}$ ) sub-basin boundaries. Ellipses represent $95 \%$ probabilities; dot and ellipse colors reflect cluster or sub-basin membership. Eigenvalues in inset plots show the relative percentage of the variation explained by the first 10 axes. 
still occurs between watersheds, as evidenced by mixing among clusters detected by individual assignment tests, the grouping of animals sampled in different major tributary (fifth-level) watersheds into the same clusters in some cases, and the failure of the landscape genetic modeling to define a landscape resistance model that predicted genetic differences.

Alternatively, these findings could reflect that translocation of 732 beaver within this region between 1939 and 1951 (ODFW, unpublished reports) obscured the relationship between landscape characteristics and gene flow by decoupling the human-facilitated movement of genes from landscape influences. But comparison of the translocation histories reconstructed here (Fig. 3) and individual assignments to genetic clusters (Fig. 2) suggests that landscape influenced spread of alleles introduced by translocation. For instance, the heavy translocation of beaver from central Oregon to the combined Umpqua and South Coast regions, largely 60-80 years ago, could have influenced the differentiation observed at $K=2$. Yet although genetic makeup of beaver in those regions may be more divergent as a result, the genetic structuring that we observed suggests that dispersal subsequently occurred mostly within major tributary and subbasin watersheds. Indeed, the existence of significant isolation by distance across the study area and strongly declining correlation of individual genetic differentiation with distance further indicates that such translocations have not resulted in a fully mixed population. The Alsea and combined Umpqua drainages exhibit especially large numbers of individuals of mixed ancestry, and perhaps not surprisingly, these drainages also have the highest numbers of recorded translocation releases. The lack of heterozygote deficit in those drainages, however, suggests that such translocations occurred long ago enough for the situation to reach equilibrium, or had little effect because of low survival of translocated animals.

Watersheds influenced genetic structure at basin (third level), sub-basin (fourth level), and major tributary (fifth level) scales. We conclude that watershed structure is biologically meaningful when considering potential for natural recolonization or translocating beaver to reduce humanwildlife conflict. One particularly striking spatial pattern was the alignment of the boundary between primary genetic clusters (Fig. 2A) with the boundary between the 2 thirdlevel basins (North Oregon Coastal and Southern Oregon Coastal) in the study area. Although we detected only a very weak effect of basin boundaries on gene flow in our landscape resistance modeling, perhaps because of the linear nature of the study area (Fig. 1), the genetic clustering results and PCA suggested that this division between individuals north and south of this basin boundary was important (Figs. 2 and 5). Grouping beaver by watershed at the sub-basin (fourth level) scale also was supported by AMOVA and STRUCTURE, although PCA suggested at most 4 divisions, corresponding to northern, mid-south, south, and Umpqua sections (Figs. 2 and $5 \mathrm{~B})$. We observed that proportions of populations exhibiting heterozygote deficit decreased as populations were defined at more localized scales, such that at the major tributary level (fifth level), little evidence of cryptic population structure remained. We observed strong genetic differentiation at larger spatial scales, as between basins (e.g., $F_{\mathrm{ST}}=0.192$, Necanicum and North Umpqua). Gene flow among adjacent watersheds appeared to vary; we observed substantial gene flow between Coos and Umpqua $\left(F_{\mathrm{ST}}=0.028\right.$, Table 3$)$ but strong differentiation between Coos and Siuslaw $\left(F_{\mathrm{ST}}=0.128\right)$.

We concluded that beaver dispersal distances are likely to be less than $61 \mathrm{~km}$ on this landscape. Genetic similarity among individual beaver at that scale was higher than average across all samples (Fig. 4), but genetic neighborhood size, or the scale at which spatial autocorrelation in alleles is detectable, is influenced by stepwise gene flow (Sokal and Wartenberg 1983). Thus, genetic neighborhood size likely exceeds typical dispersal distance. Close relationships $(r>0.4)$ among individuals occurred predominately for those captured within $1 \mathrm{~km}$ of each other, likely reflecting members of the same colony, but the mean distance of $14.6 \pm 2.3 \mathrm{~km}$ and maximum of $77.5 \mathrm{~km}$ suggest that longer-distance dispersals occur with some regularity. Relatedness values are best interpreted cautiously because of analytical limitations; high values can occur by chance, but the overall pattern of decline with distance is revealing (Fig. S5). The only other population genetic study of beaver in North America using high-resolution markers (7 microsatellite loci) was conducted in central Illinois (Crawford et al. 2008b), where flat ground and presumable absence of large predators such as mountain lions may facilitate dispersal and gene flow. In that study, populations separated by $>200 \mathrm{~km}$ had pairwise $F_{\mathrm{ST}}=0.068$, whereas we observed similar genetic differentiation even among neighboring watersheds (e.g., Alsea and Siuslaw; Table 3), using a similar set of molecular markers; the 9 loci retained for this analysis included the 7 employed by Crawford et al. (2008b). Although genetic structure also reflects effective population size and population history (Epps and Keyghobadi 2015), the greater genetic differentiation we observed in coastal Oregon suggests that gene flow is more complex and dispersal more constrained.

We were unable to establish a predictive model of gene flow based on landscape resistance. Several factors may explain our failure to detect strong effects of landscape variables on beaver gene flow in the study area. First, beaver may disperse through areas not suited for year-round habitation, or the landscape variables tested may have little influence on beaver dispersal behavior. For instance, dispersing through steep terrain or away from water may not impose strong costs for beaver. Second, relatively low variation in the landscape may have limited power to detect effects of habitats strongly limiting to dispersal. Third, that we observed only a weak effect of Euclidean distance, which we would expect to be strongly correlated with gene flow for organisms with limited dispersal range, suggests that historical translocations on genetic structure across the study area could have disrupted that signal and obscured more subtle landscape influences. Colony density could also influence dispersal success; beaver disperse into poor habitat when population density is high (DeStefano et al. 2006). Population density of beaver is not known, 
however, and habitat probably varies constantly because forest structure in the Coast Range is dynamic owing to tree harvest. Analytical limitations also were possible. We conducted our analysis at the individual level because distinct populations were not present in the dataset, and the additional genetic variability (i.e., noise) in individual genotypes compared to population allele frequencies can make it more difficult to detect landscape effects. Furthermore, the 100-m resolution of our geospatial data could have been too coarse to detect effects of landscape variables that beaver perceive and to which they respond at finer spatial scales; however, we tested a small subset of models at approximately $30-\mathrm{m}$ resolution and the amount of variation explained was similar. Future genetic research on this or similar systems would benefit from sampling from historical source areas for translocations that were outside the study area, to aid in interpretation of how translocation and dispersal structure genetic variation. Future research on dispersal distances of beaver in this or similar topographically complex landscapes should consider potential for movements within and between watersheds, and the potential for long-range movements of up to $61 \mathrm{~km}$.

Our findings have implications for the strategy of using beaver to enhance habitat suitability for coho salmon. Nash et al. (2021) recommended that if translocation of beaver is used as a tool for that purpose, practitioners use a processexpectation framework to identify and manage contingencies, achieve goals, and meet expectations. For example, for beaver to increase intrinsic potential for coho, beaver must survive, defend a territory, and build dams that create in-stream habitat that is accessible and beneficial to coho, and that benefit must lead to increased fitness in the native coho population. Given our observed patterns of gene flow and inferred dispersal distances, probably few if any locations within the study area are unreachable by dispersing beaver. Furthermore, Petro et al. (2015) reported that dams built by translocated beaver did not withstand high flow events, thus providing no habitat improvement for coho. Therefore, when assessing the suitability of a site for beaver, practitioners should consider whether natural recolonization is likely given watershed structure, and whether absence of beaver or dams thus reflects habitat characteristics or other factors rather than isolation.

\section{MANAGEMENT IMPLICATIONS}

If translocation of beaver is considered as a tool to increase beaver population densities with the goal of improving ecosystem services, such as providing habitat for coho salmon, we recommend practitioners first use watershed structure and distance to assess the potential for local recolonization. From our investigations of genetic structure, we conclude that beaver dispersal occurs most commonly within watersheds but likely also among adjacent watersheds in the Oregon Coast Range. Thus, natural recolonization of empty habitat likely does not require translocation if beaver are present within the major tributary (fifth level) watershed, or in adjacent major tributary watersheds. We further conclude that potential for recolonization through dispersal is still possible, albeit at lower probability, even if beaver are only present within the sub-basin (fourth level) watershed. We recommend that translocations undertaken to address human-wildlife conflict occur within sub-basin (fourth level) or major tributary (fifth level) watersheds. Although that strategy could increase the potential for beaver to return to the capture site, it would minimize further disruption of genetic structure, and thus disruption of potential local adaptation.

\section{ACKNOWLEDGMENTS}

We thank all the landowners, technicians, recreational trappers, and volunteers that assisted with this study, and $\mathrm{Z}$. $\mathrm{H}$. Olson and 2 anonymous reviewers for suggestions that greatly improved this manuscript. Funding and support for this research project was provided by the Oregon Forest Industries Council, Oregon State University, and United States Department of Agriculture's National Wildlife Research Center. Data used in this study are available on reasonable request to the corresponding author.

\section{LITERATURE CITED}

Adriaensen, F., J. P. Chardon, G. De Blust, E. Swinnen, S. Villalba, H. Gulinck, and E. Matthysen. 2003. The application of 'least-cost' modelling as a functional landscape model. Landscape and Urban Planning 64:233-247.

Borcard, D., and P. Legendre. 2012. Is the Mantel correlogram powerful enough to be useful in ecological analysis? A simulation study. Ecology 93:1473-1481.

Bray, J. R., and J. T. Curtis. 1957. An ordination of the upland forest communities of southern Wisconsin. Ecological Monographs 27:325-349.

Cassola, F. 2016. Castor canadensis. The IUCN Red List of Threatened Species 2016:e.T4003A22187946.

Crawford, J. C., Z. W. Liu, T. A. Nelson, C. K. Nielsen, and C. K. Bloomquist. 2008a. Isolation and characterization of microsatellite loci in the beaver (Castor canadensis). Molecular Ecology Resources 8:616-618.

Crawford, J. C., Z. W. Liu, T. A. Nelson, C. K. Nielsen, and C. K. Bloomquist. 2008b. Microsatellite analysis of mating and kinship in beavers (Castor canadensis). Journal of Mammalogy 89:575-581.

Cushman, S. A., and K. McGarigal. 2004. Hierarchical analysis of forest bird species-environment relationships in the Oregon Coast Range. Ecological Applications 14:1090-1105.

Cushman, S. A., K. S. McKelvey, J. Hayden, and M. K. Schwartz. 2006. Gene flow in complex landscapes: testing multiple hypotheses with causal modeling. American Naturalist 168:486-499.

DeStefano, S., K. K. G. Koenen, C. M. Henner, and J. Strules. 2006. Transition to independence by subadult beavers (Castor canadensis) in an unexploited, exponentially growing population. Journal of Zoology 269:434-441.

Earl, D. A., and B. M. von Holdt. 2012. STRUCTURE HARVESTER: a website and program for visualizing STRUCTURE output and implementing the Evanno method. Conservation Genetics Resources 4:359-361.

Elbroch, L. M., J. Feltner, and H. B. Quigley. 2017. Stage-dependent puma predation on dangerous prey. Journal of Zoology 302:164-170.

Epps, C. W., and N. Keyghobadi. 2015. Landscape genetics in a changing world: disentangling historical and contemporary influences and inferring change. Molecular Ecology 24:6021-6040.

Epps, C. W., J. D. Wehausen, V. C. Bleich, S. G. Torres, and J. S. Brashares. 2007. Optimizing dispersal and corridor models using landscape genetics. Journal of Applied Ecology 44:714-724.

Evanno, G., S. Regnaut, and J. Goudet. 2005. Detecting the number of clusters of individuals using the software STRUCTURE: a simulation study. Molecular Ecology 14:2611-2620.

Excoffier, L., G. Laval, and S. Schneider. 2005. Arlequin ver. 3.0: an integrated software package for population genetics data analysis. Evolutionary Bioinformatics Online 1:47-50.

Fox, J., and S. Weisberg. 2011. An R companion to applied regression, second edition. Sage, Thousand Oaks, California, USA.

Gille, D. A., M. R. Buchalski, D. Conrad, E. S. Rubin, A. Munig, B. F. Wakeling, C. W. Epps, T. G. Creech, R. Crowhurst, B. Holton, R. 
Monello, W. M. Boyce, M. C. T. Penedo, and H. B. Ernest. 2019. Genetic outcomes of translocation of bighorn sheep in Arizona. Journal of Wildlife Management 83:838-854.

Goslee, S. C., and D. L. Urban. 2007. The ecodist package for dissimilarity-based analysis of ecological data. Journal of Statistical Software 22:1-19.

Guillot, G., and F. Rousset. 2013. Dismantling the Mantel tests. Methods in Ecology and Evolution 4:336-344.

Hiller, T. L. 2011. Oregon furbearer program report, 2010-2011. Oregon Department of Fish and Wildlife, Salem, USA.

Hood, G. A., and S. E. Bayley. 2008. Beaver (Castor canadensis) mitigate the effects of climate on the area of open water in boreal wetlands in western Canada. Biological Conservation 141:556-567.

Jakobsson, M., and N. A. Rosenberg. 2007. CLUMPP: a cluster matching and permutation program for dealing with label switching and multimodality in analysis of population structure. Bioinformatics 23:1801-1806.

Jombart, T. 2008. Adegenet: a R package for the multivariate analysis of genetic markers. Bioinformatics 24:1403-1405.

Kalinowski, S. T., M. L. Taper, and T. C. Marshall. 2007. Revising how the computer program CERVUS accommodates genotyping error increases success in paternity assignment. Molecular Ecology 16:1099-1106.

Kebbe, C. E. 1960. Oregon's beaver story. Oregon State Game Commission Bulletin 15:3-6.

Law, A., F. McLean, and N. J. Willby. 2016. Habitat engineering by beaver benefits aquatic biodiversity and ecosystem processes in agricultural streams. Freshwater Biology 61:486-499.

Lizarralde, M. S., G. Bailliet, S. Poljak, M. Fasanella, and C. Giulivi. 2008. Assessing genetic variation and population structure of invasive North American beaver (Castor canadensis Kuhl, 1820) in Tierra Del Fuego (Argentina). Biological Invasions 10:673-683.

Lynch, M., and K. Ritland. 1999. Estimation of pairwise relatedness with molecular markers. Genetics 152:1753-1766.

Manel, S., and R. Holderegger. 2013. Ten years of landscape genetics. Trends in Ecology \& Evolution 28:614-621.

Mantel, N. 1967. Detection of disease clustering and a generalized regression approach. Cancer Research 27:209-220.

Mayer, M., A. Zedrosser, and F. Rosell. 2017. Extra-territorial movements differ between territory holders and subordinates in a large, monogamous rodent. Scientific Reports 7:15261.

McCaffery, M., and L. Eby. 2016. Beaver activity increases aquatic subsidies to terrestrial consumers. Freshwater Biology 61:518-532.

McClintic, L. F., G. M. Wang, J. D. Taylor, and J. C. Jones. 2014. Movement characteristics of American beavers (Castor canadensis). Behaviour 151:1249-1265.

McCormick, M. K., H. E. A. Brooks, and D. F. Whigham. 2016. Microsatellite analysis to estimate realized dispersal distance in Phragmites australis. Biological Invasions 18:2497-2504.

McNew, L. B., and A. Woolf. 2005. Dispersal and survival of juvenile beavers (Castor canadensis) in southern Illinois. American Midland Naturalist 154:217-228.

McRae, B. H. 2006. Isolation by resistance. Evolution 60:1551-1561.

Morzillo, A. T., and M. D. Needham. 2015. Landowner incentives and normative tolerances for managing beaver impacts. Human Dimensions of Wildlife 20:514-530.

Nash, C., G. E. Grant, S. Charnley, J. B. Dunham, H. Gosnell, M. B. Hausner, D. S. Pilliod, and J. D. Taylor. 2021. Great expectations: deconstructing the process pathways underlying beaver-related restoration. Bioscience 71:249-267.

Oregon Department of Fish and Wildlife [ODFW]. 2017. Requirements for relocation of beaver in Oregon. https://www.dfw.state.or.us/wildlife/ living_with/docs/Oregon_Beaver_Relocation_Requirements_Forms.pdf. Accessed 20 Aug 2020

Parker, H., P. Nummi, G. Hartman, and F. Rosell. 2012. Invasive North American beaver Castor canadensis in Eurasia: a review of potential consequences and a strategy for eradication. Wildlife Biology 18:354-365.

Pelz-Serrano, K., A. Munguia-Vega, A. J. Piaggio, M. Neubaum, P. Munclinger, A. Partl, C. Van Riper, and M. Culver. 2009. Development of nine new microsatellite loci for the American beaver, Castor canadensis (Rodentia: Castoridae), and cross-species amplification in the European beaver, Castor fiber. Molecular Ecology Resources 9:551-554.
Petro, V. M., J. D. Taylor, and D. M. Sanchez. 2015. Evaluating landowner-based beaver relocation as a tool to restore salmon habitat. Global Ecology and Conservation 3:477-486.

Petro, V. M., J. D. Taylor, D. M. Sanchez, and K. M. Burnett. 2018. Methods to predict beaver dam occurrence in coastal Oregon. Northwest Science 92:278-289.

Pilliod, D. S., A. T. Rohde, S. Charnley, R. R. Davee, J. B. Dunham, H. Gosnell, G. E. Grant, M. B. Hausner, J. L. Huntington, and C. Nash. 2018. Survey of beaver-related restoration practices in rangeland streams of the western USA. Environmental Management 61:58-68.

Pollock, M. M., T. J. Beechie, J. M. Wheaton, C. E. Jordan, N. Bouwes, N. Weber, and C. Volk. 2014. Using beaver dams to restore incised stream ecosystems. Bioscience 64:279-290.

Pritchard, J. K., M. Stephens, and P. Donnelly. 2000. Inference of population structure using multilocus genotype data. Genetics 155:945-959.

R Core Team. 2018. R: a language and environment for statistical computing. R Foundation for Statistical Computing, Vienna, Austria.

Rainbolt, R. E. 1999. Historic beaver populations in the Oregon Coast Range. Oregon Department of Fish and Wildlife, Salem, USA.

Rousset, F. 2008. GENEPOP' 007: a complete re-implementation of the GENEPOP software for Windows and Linux. Molecular Ecology Resources 8:103-106.

Seaber, P. R., F. P. Kapinos, and G. L. Knapp. 1987. Hydrologic unit maps. U.S. Geological Survey, Reston, Virginia, USA.

Shah, V., and B. McRae. 2008. Circuitscape: a tool for landscape ecology. Proceedings of the Python in Science Conference 7:62-66.

Silverman, N. L., B. W. Allred, J. P. Donnelly, T. B. Chapman, J. D. Maestas, J. M. Wheaton, J. White, and D. E. Naugle. 2019. Low-tech riparian and wet meadow restoration increases vegetation productivity and resilience across semiarid rangelands. Restoration Ecology 27:269-278.

Slatkin, M. 1995. A measure of population subdivision based on microsatellite allele frequencies. Genetics 139:457-462.

Sokal, R. R., and D. E. Wartenberg. 1983. A test of spatial autocorrelation analysis using an isolation-by-distance model. Genetics 105:219-237.

Spear, S. F., N. Balkenhol, M. J. Fortin, B. H. McRae, and K. Scribner. 2010. Use of resistance surfaces for landscape genetic studies: considerations for parameterization and analysis. Molecular Ecology 19:3576-3591.

Taylor, J. D., G. K. Yarrow, and J. E. Miller. 2017. Beavers. Wildlife Damage Management Technical Series. USDA, APHIS, Fort Collins, Colorado, USA.

van Etten, J. 2017. gdistance: distances and routes on geographical grids. Version 1.1-9. https://cran.r-project.org/web/packages/gdistance/index.html

Wainwright, T. C., and L. A. Weitkamp. 2013. Effects of climate change on Oregon coast coho salmon: habitat and life-cycle interactions. Northwest Science 87:219-242.

Wang, J. 2010. COANCESTRY: a program for simulating, estimating and analysing relatedness and inbreeding coefficients. Molecular Ecology Resources 11:141-145.

Weber, N., N. Bouwes, M. M. Pollock, C. Volk, J. M. Wheaton, G. Wathen, J. Wirtz, and C. E. Jordan. 2017. Alteration of stream temperature by natural and artificial beaver dams. Plos One 12:e0176313.

Western Regional Climate Center. 2008. Local climate data summaries for the western United States. https://wrcc.dri.edu/Climate/west_lcd.php. Accessed 18 May 2017.

Worthington Wilmer, J., C. Elkin, C. Wilcox, L. Murray, D. Niejalke, and H. Possingham. 2008. The influence of multiple dispersal mechanisms and landscape structure on population clustering and connectivity in fragmented artesian spring snail populations. Molecular Ecology 17:3733-3751.

Wright, S. 1943. Isolation by distance. Genetics 28:114-138.

Wright, S. 1946. Isolation by distance under diverse systems of mating. Genetics 31:39-59.

Associate Editor: Zach Olson

\section{SUPPORTING INFORMATION}

Additional supporting information may be found in the online version of this article at the publisher's website. 